\title{
Endovascular repair of the aortic arch: To see the future, we need to look beyond
}

\author{
Ludovic Canaud, MD, $\mathrm{PhD}$
}

\author{
From the Department of Thoracic and Cardiovascular Surgery, Montpellier, France. \\ Disclosures: Author has nothing to disclose with regard to commercial support. \\ Received for publication July 20, 2017; accepted for publication July 31, 2017; available ahead of print Aug 29, \\ 2017. \\ Address for reprints: Ludovic Canaud, MD, PhD, Service de Chirurgie Vasculaire et Thoracique, Hôpital A de \\ Villeneuve, 191 av Doyen Gaston Giraud, 34090 Montpellier, France (E-mail: ludoviccanaud@ hotmail.com). \\ J Thorac Cardiovasc Surg 2017;154:e79 \\ $0022-5223 / \$ 36.00$ \\ Copyright (C) 2017 by The American Association for Thoracic Surgery \\ http://dx.doi.org/10.1016/j.jtcvs.2017.07.050
}

The frequency of reports citing the use of endovascular techniques to treat the aortic arch is increasing. ${ }^{1}$ There are at present several endovascular treatment options for aortic arch lesions. Techniques of hybrid arch repair, chimney grafts, and branched stent grafts have all been described for patients with aortic arch disease. Currently, there is no Food and Drug Administration-approved off-the-shelf device for aortic arch repair, although significant progress is being made.

In this issue of the Journal, D'Onofrio and colleagues ${ }^{2}$ report endovascular treatment of an aortic arch aneurysm with a modular single-branched stent graft in combination with left common carotid and left subclavian artery debranching. The outcomes at 6 months were excellent. Before we can see the future of aortic arch repair, however, we need to look beyond.

The initial benefit of endovascular repair has been to put pressure on open aortic arch surgeons to improve the outcomes of this challenging procedure. Those writing favorably about endovascular arch repair, commonly referring to a review by Moon and associates, ${ }^{3}$ appear to overstate the chief risks associated with open aortic arch surgery. The upper limit of the mortality range reported by Moon and associates ${ }^{3}$ $(16.5 \%)$ does not reflect contemporary outcomes, because the data were collected between 1978 and 1997, and the upper limit of the reported stroke rate range $(18.0 \%)$ stems from a subgroup of 30 patients undergoing isolated ascending aortic repairs. The data of Preventza and colleagues, ${ }^{4}$ who report an overall mortality of $12.5 \%$ and a stroke rate of $6.6 \%$, may more accurately reflect contemporary outcomes.

The most appealing endovascular option is the use of custom-made branched devices (with 2 branches), allowing anatomic repair while precluding the need for left common carotid revascularization. The combined multicenter world experience, consisting of 38 branched arch devices, was first reported in 2014 by Haulon and coworkers. ${ }^{5}$ A 16\% stroke rate and a $15.8 \%$ technical failure rate were reported. One important advantage of the single-branched stent graft is the simplicity of the procedure relative to multibranched stent grafts, which by decreasing the need for manipulation

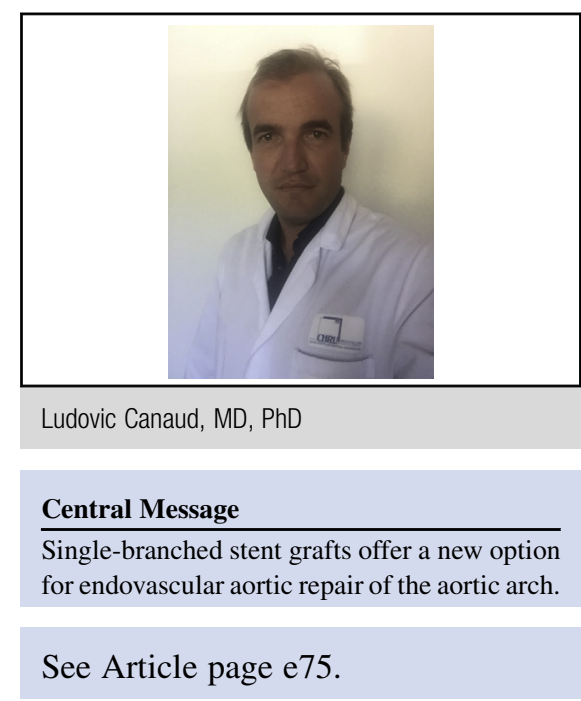

in the arch lowers the associated risk of microembolic stroke.

The main concern regarding this modern modular single branched stent-graft is its similarity to a previous modular single-branched device reported on by Chuter and colleagues ${ }^{6} 15$ years ago. At that time, the modular endovascular approach was eventually abandoned. Close examination of the design of this new stent graft suggests that the overlap between the 2 modules cannot even satisfy the 5 -cm recommendation made for the descending thoracic aorta. Considering the hostile environs of the ascending aorta such as its high pulsatility, mobility, and curvature, the durability and specifically the resistance to component separation of this modular approach will have to be proved.

\section{References}

1. Canaud L, Baba T, Gandet T, Narayama K, Ozdemir BA, Shibata T, et al. Physician-modified thoracic stent-grafts for the treatment of aortic arch lesions. J Endovasc Ther. 2017;24:542-8.

2. D'Onofrio A, Antonello M, Lachat M, Planer D, Manfrin A, Bagno A, et al Endovascular treatment of aortic arch aneurysm with a single-branched double-stage stent graft. J Thorac Cardiovasc Surg. 2017;154:e75-7.

3. Moon MC, Morales JP, Greenberg RK. The aortic arch and ascending aorta: are they within the endovascular realm? Semin Vasc Surg. 2007;20:97-107.

4. Preventza O, Coselli JS, Akvan S, Kashyap SA, Garcia A, Simpson KH, et al. The impact of temperature in aortic arch surgery patients receiving antegrade cerebral perfusion for $>30$ minutes: How relevant is it really? J Thorac Cardiovasc Surg. 2017; $153: 767-76$

5. Haulon S, Greenberg RK, Spear R, Eagleton M, Abraham C, Lioupis C, et al Global experience with an inner branched arch endograft. J Thorac Cardiovasc Surg. 2014;148:1709-16.

6. Chuter TA, Schneider DB, Reilly LM, Lobo EP, Messina LM. Modular branched stent graft for endovascular repair of aortic arch aneurysm and dissection. $J$ Vasc Surg. 2003;38:859-63. 